\title{
The impact of polycystic ovary syndrome on women's quality of life: Nursing guidelines for its management
}

\author{
Hanan Elzeblawy Hassan*1, Doaa Shehta Said Farag² \\ ${ }^{1}$ Maternal and Newborn Health Nursing, Faculty of Nursing, Beni-Suef University, Egypt \\ ${ }^{2}$ Maternal and Newborn Health Nursing, Faculty of Nursing, Helwan University, Egypt
}

Received: April 1, 2019

DOI: $10.5430 /$ cns.v7n3p42
Accepted: June 9, 2019

Online Published: June 19, 2019

\begin{abstract}
Background: Polycystic ovary syndrome (PCOS) is an uncertain-etiology heterogeneous disorder, which affects $6.0 \%$ to $10.0 \%$ of women in their reproductive age. Aim: assess phenotypic characteristics of women with PCOS, discovery the association between women's quality-of-life (QOL) and its occurrence and improve women's knowledge \& increase awareness regarding PCOS.

Methods: A descriptive cross-sectional design had been utilized on a purposive sample of 300 women in reproductive age with PCOS in the gynecological outpatient clinic at Beni-Suef General Hospital, Egypt. A structured interviewing schedule, patient's assessment record, visual-analogue-scale, Ferriman-Gallwey-Evaluation-of-Hirsutism, QOL Questionnaire, Short-Form-HealthSurvey (SF-36), and designed intervention nursing-guideline had been used for data collection.

Results: A high percentage (56.7\%) of women had a complete phenotype characteristics of PCOS. The most prevalent phenotypic characteristics were alopecia (65.0\%), irregular menses (58.7\%), and obesity/overweight (48.1\%). Statistically significant was found between women's general characteristic of PCOS and their age, body-mass-index, hirsutism, and average cycle length, $p<$ .05. Women's QOL had affected negatively by PCO Syndrome, $p<.05$.

Conclusions: PCOS is a common risk factor for acne, alopecia, hirsutism. Many factors to be associated with its phenotype as: body-mass-index, hirsutism, and average cycles length. It has a negative impact on phenotype characteristic, psychological/social domain and total QOL scale. The nursing guideline had a crucial role in the improvement of women's knowledge in allover items of women's knowledge.
\end{abstract}

Recommendation: Upgrading women's knowledge concerning PCOS with a periodic screening of women for early detection and management. Health-Promotion-Programs through different media to improve QOL for women with PCOS.

Key Words: Polycystic ovary syndrome, Quality of life, Nursing guidelines

\section{INTRODUCTION}

In the developed world, Polycystic ovary syndrome (PCOS) is the most common endocrine disorder among women of reproductive age, it affects $5 \%$ to $10 \%$ of this population, and $4.0 \%$ to $6.0 \%$ of adolescent girls and young women. ${ }^{[1]}$ The prevalence of PCOS has shown to be increased with the use of different diagnostic criteria and has recently been shown to be $26.0 \%$ in the 1 st community-based prevalence studies based on the current diagnostic criteria. ${ }^{[2]}$

PCOS is characterized by the accumulation of numerous cysts on the ovaries associated with metabolic disturbances chronic anovulation, and high male hormone levels. ${ }^{[3]}$

\footnotetext{
*Correspondence: Hanan Elzeblawy Hassan; Email: nona_nano_1712@yahoo.com; Address: Maternal and Newborn Health Nursing, Faculty of Nursing, Beni-Suef University, Egypt.
} 
The exact causes of PCOS are unknown, but most of the gynecologists' expertise think that several factors may be attributed; including genetics which could play a role. Women with PCOS are more likely to have a mother or sister with PCOS. ${ }^{[4]}$ It is, in some cases, a familial disorder, but the genetic basis of the syndrome remains unclear. Studies of family members with PCOS indicate that an autosomal dominant mode of inheritance, with premature male pattern baldness as the male phenotype, may occur. Full expression of the syndrome may require insulin abnormality and a defect in androgen biosynthesis, but no gene (or genes) has been identified. ${ }^{[5]}$

The clinical manifestation of PCOS varies widely. Women with PCOS often seek care for infertility, hyperandrogenism manifestations, and menstrual disorders. Menstrual disturbances will be commonly observed in PCOS include prolonged/erratic menstrual-bleeding, oligomenorrhea, and amenorrhea. However, $30.0 \%$ of women with PCOS will have normal menstruation. Approximately $85.0 \%$ to $90.0 \%$ of women with oligomenorrhea have PCOS while $30.0 \%$ to $40.0 \%$ of women with amenorrhea will have PCOS. ${ }^{[6]}$

According to the American College of Obstetricians and Gynecologists, ${ }^{[7]}$ the diagnosis of PCOS using the Rotterdam/AES criteria depends on the use of a reliable method to describe the morphology of the polycystic ovarian. The criteria for polycystic ovarian morphology proposed by the Rotterdam consensus group includes the presence of 12 or more follicles measuring between $2 \mathrm{~mm}$ to $9 \mathrm{~mm}$ in diameter and/or an increased ovarian volume of greater than 10 $\mathrm{cm}^{3}$. This presentation in even one ovary sufficiently defines the polycystic ovary. However, since that time, significant advancements in ultrasound image technology have been made, improving resolution and allowing for the detection of smaller follicles. This had prompted calls for revisiting the criteria used to define the morphology of a polycystic ovarian.

Risk factors for PCOS in adults include obesity, especially upper body obesity. Obesity is present in at least $30.0 \%$ of women with PCOS. Hyperinsulinemia is secondary to insulin resistance, insulin resistance will affect $50 \%$ to $70 \%$ of women with PCOS leading to a number of comorbidities including glucose intolerance, metabolic syndrome, dyslipidemia, and hypertension. ${ }^{[5]}$

Women with PCOS are at-risk group for psychological and behavioral disorders such as bipolar disorder, negative emotions, frustration, eating disorder, sadness, anxiety, and reduced one's quality of life (QOL). PCOS frequently manifests itself at puberty or during young adulthood with features like obesity and hirsutism, which affect women's self-image, self-esteem, and QOL of young women. ${ }^{[8]}$

Women with PCOS experience psychopathology more often than women without PCOS. The recent consensus report on women's health aspects of PCOS recommended that mental health issues should be considered in every woman with PCOS, and highlighted the need for the development of appropriate interventions. ${ }^{[9]} \mathrm{PCOS}$, as one of the most frequent endocrine disorders in adolescent/young females, has an important influence on ones' QOL.

Quality-of-Life (QOL) has become an increasingly attractive subject in recent decades, drawing attention from both enthusiasts and researchers. ${ }^{[10]}$

Health-related-quality-of-life (HRQOL) is a QOL term that takes into account the impact an illness has on an individual's QOL. ${ }^{[11,12]} \mathrm{QOL}$ issues are of interest in oncology because effective modern methods of treatment and detection have led to an increase in the number of long-term survivors. ${ }^{[13]}$ QOL has grown significantly with numerous studies that were directed in this research area. ${ }^{[14]}$ QOL encompasses all impacts of disease and reflects an appraisal of disease that is affected in a complex way by the person's physical health, psychological state, level of independence, social relationships, personal beliefs and their relationship to salient features of their environment. ${ }^{[14,15]}$

QOL is defined as a multi-dimensional concept that includes domains-related-to physical/mental/social aspects (see Figure 1). ${ }^{[14,16,17]}$ It goes beyond direct measures of population health, and causes of death, and focuses on the impact health status has on QOL. ${ }^{[18]}$ According to Kobau et al., QOL is well-being, which assesses the positive aspects of a one's life, such as life satisfaction and positive emotions. Well-being is a relative state where one maximizes physical/mental/social functioning in the context of supportive environments to live a productive life, full, and satisfying life. ${ }^{[19]}$

Treatment for women with PCOS depends on the symptoms with which a patient presents. Symptoms typically fit into 3 categories: (1) menstruation-related-disorders, (2) androgenrelated-symptoms, (3) and infertility. Management includes oral contraceptive pills (OCPs) is the first-line for treat menstrual irregularities and acne, management of hirsutism in premenopausal women. Laser therapy is recommended as a safe method to reduce excess body hair. spironolactone is commonly used in combination with OCPs for treatment of PCOS related-symptoms. ${ }^{[20]}$

Treatment options for infertility include Clomid, ovulation induction with gonadotropins and laparoscopic-ovariandrilling (LOD), and in-vitro fertilization (IVF). Letrozole and Glucophage play an important role in ovulation induction. 
Spironolactone and finasteride are used to treat symptoms of androgen excess. ${ }^{[3]}$ A proper and accurate diagnosis is now becoming more and more significant because of PCOS's impact on patient condition, treatment, and QOL.

Weight loss can improve circulating androgen levels, along with providing other metabolic benefits for patients with PCOS. ${ }^{[7]}$ Weight loss has been consistently successful in reducing insulin resistance and restore ovulation and fertility. Current conservative treatment emphasizes sustainable weight loss through dietary therapy and exercise. ${ }^{[21]}$

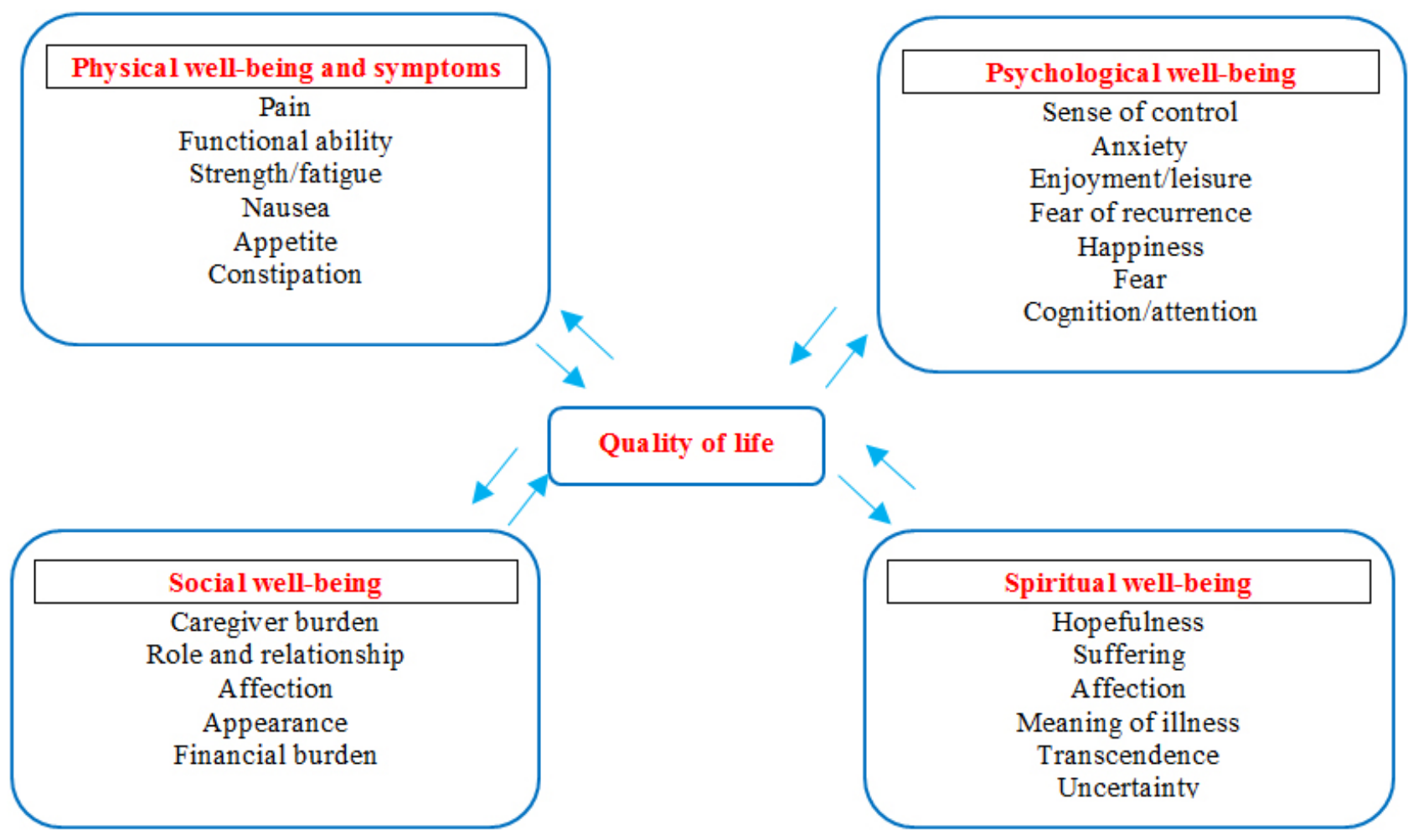

Figure 1. Dimensions of QOL affect by cancer ${ }^{[17]}$

In the healthcare delivery system, nurses are the ones in charge of the quality of care provided to the women all-over lifespan, they have a very crucial important role in women's awareness raising and counseling. ${ }^{[22-24]}$ PCOS is a public health concern with many psychological and physical consequences that do undermine women's QOL, the maternity nurse in-turn had a crucial role in counseling for the decline of this phenomenon. ${ }^{[25]}$

Nurses can have a positive impact on women with PCOS through counseling and education, Provide support for women dealing with negative self-image secondary to the physical manifestations of PCOS, through education; help the women understand the syndrome and it is associated risk factors to prevent long-term health problems, encourage woman to make positive lifestyle changes and make community referrals to local support groups to help the woman built her coping skills. ${ }^{[26]}$ Data related to the PCOS among women in Beni-Suef city and their QOL is scarce. Therefore, there is a need to assess the magnitude of the problem and its relation to the patient's QOL.

\section{Aim of this study}

Previous literature spoke about the pivotal-role of nurses, directly by participation in the screening programs and indirectly by raising the awareness of women. ${ }^{[27]}$ Therefore, it is crucial for nurses to be aware of adequate and necessary knowledge in order to conduct their future tasks, as nurses, appropriately. ${ }^{[28]}$ As nurses comprise the greatest portion of the health care system, they are the key persons in the healthcare delivery system. The current study was conducted to determine the impact of PCOS on women's QOL through the following mentioned objectives:

(1) Assess phenotypic characteristics of women with PCOS.

(2) Discovery the association between women's QOL and the occurrence of PCOS at Beni-Suef city.

(3) Design a plan for nursing intervention used to overcome this problem through the improvement of women's knowl- 
edge and increase their awareness regarding PCOS.

\section{SUBJECTS AND METHODS}

\subsection{Research design}

A cross-sectional descriptive study was utilized in this study.

\subsection{Subjects \& setting}

A purposive sample of on 300 women in reproductive age admitted with PCOS in the Outpatient Clinic of the Gynecological Department of Beni-Suef General Hospital, Egypt from 1st March 2018 till the end of February 2019 was included. All gynecological patient attending the study setting was selected during a study period of 12 months depending on the following inclusion criteria: Patient's aged 17-39 years who agreed to participate, still menstruating $\&$ have intact uterus and ovaries. Not taking any hormonal medical treatment. Include two out of three of the following: Polycystic-ovaries, oligo/anovulation and signs of hyperandrogenism to be included in the study from the gynecologic patients' list during the study period. The patient who took previous hormonal therapy or those who weren't complete the study was excluded from the sample.

\subsection{Tools of data collection}

Data of the current study were collected using the following tools:

(1) A structured interviewing schedule that includes personal, medical, and obstetrical history such as age, parity, and body mass index, number of deliveries, obstetric problem \& operations associated with pregnancy, current complaint such as hirsutism.

(2) Patient's assessment record which includes general examination such as height, weight and vital signs, lab test, patient's phenotype characteristics and results of ultrasonography.

(3) Visual analogue scale to score pain intensity during menstruation: ${ }^{[29]}$ A self-reported device consisting of $10 \mathrm{~cm}$ straight line, which represented a continuum of pain intensity.

(4) Ferriman Gallwey Evaluation of Hirsutism: ${ }^{[30]}$ It is used to score the degree of excess male pattern body hair on a woman shown in four different degrees of severity in 11 different body parts: namely the lower leg \& thigh, upper lip, upper \& lower back, chest, upper abdomen \& abdomen, arm $\&$ forearm, and chin.

(5) QOL Questionnaire for women's with PCOS:[31] It is used to measure specific PCOS disease-related physical/psychological/social dysfunction. It is a 26-item questionnaire that contains 6 subscales; emotional-disturbances
(8 items), hirsutism (5 items), infertility (4 items), weight (5 items), and menstrual (4 items). It was modified and added four questions to be 30 items and in order to evaluate issues associated with acne.

(6) The Short Form Health Survey (SF-36): ${ }^{[32]}$ to assess the QOL is a well-generic-validated-instrument that measures 9 subscales: physical functioning, role limitations related to physical problems, energy and vitality, bodily pain, general health perception, change in health, social functioning, role limitations related to emotional problems, and mental health. The score for each subscale ranges from 0-100 where higher scores indicate better conditions.

(7) Designed intervention nursing program: The objectives of this training program is to improve women's knowledge and awareness regarding PCOS, and promote early detection/management of PCOS.

\subsubsection{Validity and reliability of the tool}

The questionnaire was developed in consultation with two gynecologists, two maternity \& gynecological nursing professors, and an expert in questionnaire validation. The validity of the used tool was evaluated by a health-care specialists and modifications were done accordingly based on their judgment, while its reliability assessed by piloting $\&$ measuring the related Cronbach Alpha value (Alpha = 0.88).

\subsubsection{Administrative and ethical considerations}

Official permission was obtained by submission of an official letter from the Faculty of Nursing to the responsible authorities of the study-setting to obtain permission for data collection. All ethical issues were taken into the researcher's consideration during all phases of the study; the researcher maintained the anonymity/confidentiality of the subjects. The researcher introduced herself to the patient and explained the nature of the study to every patient and asked questions in Arabic for all patients. Patients were enrolled voluntarily after their oral consent.

\subsubsection{Pilot study}

Pilot study was conducted on 30 women with PCOS (10\% of the total number) to test the feasibility and applicability of the tools, and to estimate the time needed for data collection. Necessary modification/omission/addition was followed as needed according to the results of the conducted pilot study.

\subsection{Program sessions}

The guideline, designed by the researchers, included 4 sessions: 60 minutes each, on one day. In the opening ceremony session, the researcher introduces herself to the participants and get their expectations, then she distributes the pre-test to assess participants' baseline-knowledge regarding PCOS. 
The 1st session covers an introduction and overview regard- Researcher adopted a problem-solving approach in our sesing PCOS. The 2nd session illustrates the phenotypes characteristics, etiology, clinical features and complications of PCOS. The 3rd session discussed the therapeutic measures for PCOS and its associated ministrations as acne, hirsutism, etc. The 4th session covers all points regarding the healthy instructions and QOL for a patient with PCOS. The guideline program was closed by distribution of the post-test to evaluate the effect of the guidelines on participants' knowledge. sions which allowed participants to participate and discuss their concerns. During the sessions, short films, presentations, illustrated pictures, and group discussion were held. At the end of each session, the researcher summarized the important points of this session and the participants were encouraged to ask and show their personal experience. Booklets, brochures, and leaflets, supported by illustrated figures, were distributed as take-home notes (see Table 1).

Table 1. Overview of the elements in the nursing guidelines on women's knowledge regarding PCOS and its management (duration 4 hours)

\begin{tabular}{|c|c|c|c|}
\hline No. & Elements & Objectives & Method \\
\hline \multicolumn{2}{|c|}{ Opening Ceremony } & $\begin{array}{l}\text { - The researcher introduces herself to the participants } \\
\text { - Welcome and presentation sessions objectives } \\
\text { - Enumerate the participants' expectations on a Philip chart } \\
\text { - Distribution of pre-test }\end{array}$ & - Philip chart \\
\hline Session (1) & $\begin{array}{l}\text { An overview regarding } \\
\text { PCOS }\end{array}$ & $\begin{array}{l}\text { - State an introduction about Polycystic Ovary Syndrome } \\
\text { - } \quad \text { Define PCOS } \\
\text { - } \quad \text { Illustrate the prevalence of PCOS } \\
\text { - } \quad \text { List the risk factor of PCOS }\end{array}$ & - Power point \\
\hline Session (2) & $\begin{array}{l}\text { Knowledge regarding the } \\
\text { Phenotypes characteristics, } \\
\text { etiology, clinical features } \\
\text { and complications of PCOS }\end{array}$ & $\begin{array}{l}\text { - Recognize Phenotypes characteristics PCOS } \\
\text { - Recall the etiology of PCOS } \\
\text { Describe the clinical features of PCOS } \\
\text { a. Mention general manifestations } \\
\text { b. Mention local manifestations } \\
\text { - Summarize complications of PCOS } \\
\text { c. Short-term complications } \\
\text { d. Long-term complications }\end{array}$ & $\begin{array}{l}\text { - } \\
\text { - } \quad \text { Pictures }\end{array}$ \\
\hline Session (3) & $\begin{array}{l}\text { Knowledge regarding } \\
\text { therapeutic measures } \\
\text { for PCOS }\end{array}$ & $\begin{array}{l}\text { - Mention the measures for the associated manifestations of PCOS (Acne, } \\
\text { Hirsutism, Alopecia) } \\
\text { Mention the therapeutic measures for PCOS } \\
\text { a. Medical } \\
\text { b. Surgical }\end{array}$ & $\begin{array}{ll}\text { - } & \text { Power point } \\
\text { - } & \text { Short films } \\
\text { - } & \text { Pictures }\end{array}$ \\
\hline Session (4) & $\begin{array}{l}\text { Knowledge regarding the } \\
\text { healthy instructions and } \\
\text { QOL for patient with PCOS }\end{array}$ & $\begin{array}{l}\text { - Mention the healthy instructions and QOL for a patient with PCOS } \\
\text { A. Healthy diet } \\
\text { - Describe the healthy diet for a patient with PCOS } \\
\text { - List the types of diets which will be allowed for a patient with PCOS } \\
\text { - List the types of diets which will not be allowed for a patient with PCOS } \\
\text { - Formulate a balanced diet for a patient with PCOS } \\
\text { - Compose an example for a healthy diet during the day for a patient with } \\
\text { PCOS } \\
\text { B. Exercise therapy } \\
\text { Demonstrate physical exercises for PCOS } \\
\text { C. Body weight } \\
\text { List methods for reducing obesity and maintain ideal body weight }\end{array}$ & $\begin{array}{ll}\text { - } & \text { Power point } \\
\text { - } & \text { Video } \\
\text { - } & \text { Pictures }\end{array}$ \\
\hline Closing & & - Distribution of post-test & $\begin{array}{l}\text { - Thanks to } \\
\text { participants }\end{array}$ \\
\hline
\end{tabular}




\subsection{Statistical analysis}

All collected data were tabulated and analyzed statistically by using SPSS 20.0 for windows. Mean, standard deviation (Mean $\pm S D$ ) and number and percent (for qualitative data) were used for descriptive statistics. Student's test (to compare between two independent means), Paired " $t$ " test (to compare between different outcomes in the same group), and Chi-Square (to compare between dependent percentages) were used for analytical statistics. Column and Pie chart are used for graphics presentation. Level of significance ( $p$-value) was measured at .05; $p>.05=$ Non-significant and $p<.05=$ Significant.

\section{RESUlts}

Table 2 shows that the highest percentage $(72.4 \%)$ of the sample was between 20-39 years ages. Almost three-quarters of the subjects were illiterate $\&$ had Primary level of education and were living in rural areas $(71.0 \% \& 37.3 \%$ respectively), around two thirds $(61.0 \%)$ of the sample were housewives. The same table demonstrates that around half $(48.1 \%)$ of the studied women were overweight and obese. Hirsutism was observed in $16.4 \%$ of the sample in the form mustache hair, facial hair, abdomen hair, chin hair, and chest hair $(44.9 \%$, $28.6 \%, 8.2 \%, 14.2 \%, 4.1 \%)$, respectively. As for alopecia, this was evident by almost two-thirds of the sample (65.0\%).

Table 2. Socio-demographic and general characteristics of the studied women $(n=300)$

\begin{tabular}{|c|c|c|c|}
\hline & Variables & No & $\%$ \\
\hline \multirow{3}{*}{ Age per years } & $17-20$ & 83 & 27.6 \\
\hline & $20-39$ & 217 & 72.4 \\
\hline & Mean $\pm S D$ & $25 \pm 5.41$ & \\
\hline \multirow{14}{*}{$\begin{array}{l}\text { Socio-demographic } \\
\text { characteristics }\end{array}$} & Education & & \\
\hline & Illiterate & 129 & 43.0 \\
\hline & Primary education & 84 & 28.0 \\
\hline & Secondary education & 39 & 13.0 \\
\hline & University education & 48 & 16.0 \\
\hline & Residence & & \\
\hline & Rural & 112 & 37.3 \\
\hline & Urban & 188 & 62.7 \\
\hline & Occupation & & \\
\hline & Working & 117 & 39.0 \\
\hline & House wives & 183 & 61.0 \\
\hline & Marital status & & \\
\hline & Married & 190 & 63.4 \\
\hline & Not married & 110 & 36.6 \\
\hline \multirow{18}{*}{$\begin{array}{l}\text { General } \\
\text { characteristics }\end{array}$} & Body Mass Index (BMI) & & \\
\hline & Normal body weight (BMI: $18.5-24.9 \mathrm{~kg} / \mathrm{m}^{2}$ ). & 134 & 44.6 \\
\hline & Over weight (BMI: $\left.25-29.9 \mathrm{~kg} / \mathrm{m}^{2}\right)$. & 98 & 32.8 \\
\hline & Obese (BMI; of 30 or greater $\left.\mathrm{kg} / \mathrm{m}^{2}\right)$. & 46 & 15.3 \\
\hline & Under weight (BMI: >18.5 kg/m²). & 22 & 7.4 \\
\hline & Hirsutism & 49 & 16.4 \\
\hline & Mustache hair & 22 & 44.9 \\
\hline & Facial hair & 14 & 28.6 \\
\hline & Abdomen hair & 4 & 8.2 \\
\hline & Chin hair & 7 & 14.2 \\
\hline & Chest hair & 2 & 4.1 \\
\hline & Acne & 28 & 9.3 \\
\hline & Alopecia & 195 & 65.0 \\
\hline & Insulin resistance & 36 & 12.0 \\
\hline & Breast size & & \\
\hline & Small & 29 & 9.6 \\
\hline & Average & 220 & 73.4 \\
\hline & Large & 51 & 17.0 \\
\hline
\end{tabular}


Concerning menstruation characteristics Table 3 shows that more than three-fifths of women $(60.7 \%)$ were in the age at menarche group of 13 to 14 years, with a mean of $13.3 \pm$ 1.2. Most of them had irregular period, oligomenorrhea and severe pain $(58.7 \%, 78.0 \% \& 63.3 \%)$, respectively.

Table 3. Menstrual history of the studied women $(n=300)$

\begin{tabular}{lll}
\hline Parameters & No & $\%$ \\
\hline Age at menarche & 43 & 14.3 \\
$10-12$ & 182 & 60.7 \\
$13-14$ & 75 & 25.0 \\
15 or more & $13.3 \pm 1.2$ & \\
Mean \pm SD & & \\
Regularity & 124 & 41.3 \\
Regular & 176 & 58.7 \\
Irregular & \\
Interval & 50 & \\
Normal (28-35) & 234 & 16.7 \\
Oligomenorrhea $>35$ & 16 & 78.0 \\
Amenorrhea $>90$ & $27.4 \pm 3.1$ & 5.3 \\
Mean $\pm S D$ & & \\
Pain & 48 & 16.0 \\
Mild & 62 & 20.7 \\
Moderate & 190 & \\
Sever & & \\
\hline
\end{tabular}

Concerning women's obstetric history, Table 4 shows that about two thirds $(64.0 \%)$ of women had no previous pregnancy. Meanwhile, 44 of all $50(88.0 \%)$ had less than 4 delivers and $36.0 \%$ had a history of previous abortion, of those nearly one fourth $(24.1 \%)$ were exposed to habitual abortion. Few women 34 (11.3\%) had associated problems with pregnancy such as: gestational diabetes mellitus (GDM) and Pregnancy-induced hypertension (PIH); (64.7\% \& 35.3\%), respectively.

Table 5 reveals that nearly two-thirds $(62.7 \%)$ of women had ovarian stimulation being prescribed for them to treat infertility. Moreover, more than half $(55.3 \%)$ of women were previously exposed to gynecological operations. Fortyeight percent of the studied women suffered from infertility; of those, the majority $(62.5 \%)$ had primary infertility. As for contraceptive history, only $18.7 \%$ used a contraceptive method, which was mostly IUD, or OCPs $(58.9 \% \& 32.2 \%)$, respectively.

Figure 2 illustrates that more than one-third $(114 ; 38.0 \%)$ of women had a negative family history of PCO syndrome. While more than one-half of women $(186 ; 62.0 \%)$ had a positive family history of PCO syndrome. Of those, the mother constituted the highest percentage $(40.9 \%)$ followed by the sister, aunts (mother's sister, and father's sister), $27.9 \%$, $20.5 \%, 10.7 \%$, respectively.

Table 4. Obstetrical history of the studied women $(n=300)$

\begin{tabular}{lll}
\hline Parameters & No & \% \\
\hline Gravidity & & \\
Nulligravida & 192 & 64.0 \\
Multigravida & 108 & 36.0 \\
$1-3$ & 74 & 68.5 \\
$\geq 4$ & 34 & 31.5 \\
Parity & & \\
Nullipara & 58 & 53.7 \\
Multipara & 50 & 46.3 \\
$1-3$ & 44 & 88.0 \\
$\geq 4$ & 6 & 12.0 \\
History of abortion & & \\
No previous abortion & 192 & 64.0 \\
Had a previous abortion & 108 & 36.0 \\
$1-3$ & 82 & 75.9 \\
$\geq 4$ & 26 & 24.1 \\
Pregnancy problems & & \\
No & 166 & 88.7 \\
Yes & 34 & 11.3 \\
GDM & 22 & 64.7 \\
PIH & 12 & 35.3 \\
\hline
\end{tabular}

Table 5. Gynecological history of the studied women $(\mathrm{n}=$ 300)

\begin{tabular}{lll}
\hline Parameters & No & $\%$ \\
\hline Ovarian stimulation & & \\
$\quad$ Yes & 188 & 62.7 \\
No & 112 & 37.3 \\
Gynecological operation & & \\
$\quad$ Yes & 166 & 55.3 \\
No & 134 & 44.7 \\
Infertility problem & & \\
No & 156 & 52.0 \\
Yes & 144 & 48.0 \\
$\quad$ Primary infertility & 90 & 62.5 \\
$\quad$ Secondary infertility & 54 & 37.5 \\
Contraception & & \\
No used & 244 & 81.3 \\
Used contraception & 56 & 18.7 \\
IUD & 33 & 58.9 \\
Pills & 18 & 32.2 \\
Injection & 5 & 8.9 \\
\hline
\end{tabular}




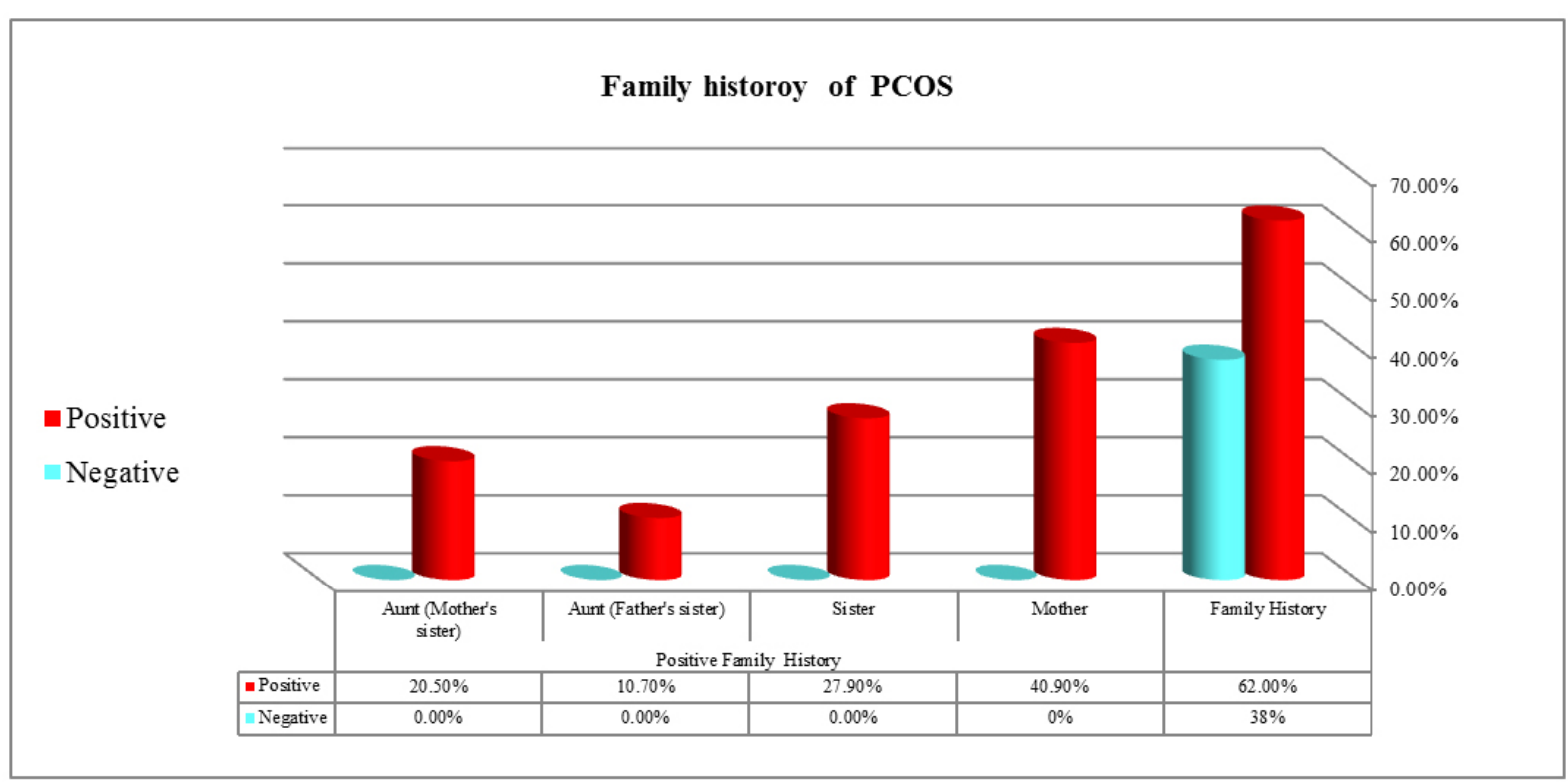

Figure 2. Distribution of the studied women according to the to their family history $(\mathrm{n}=300)$

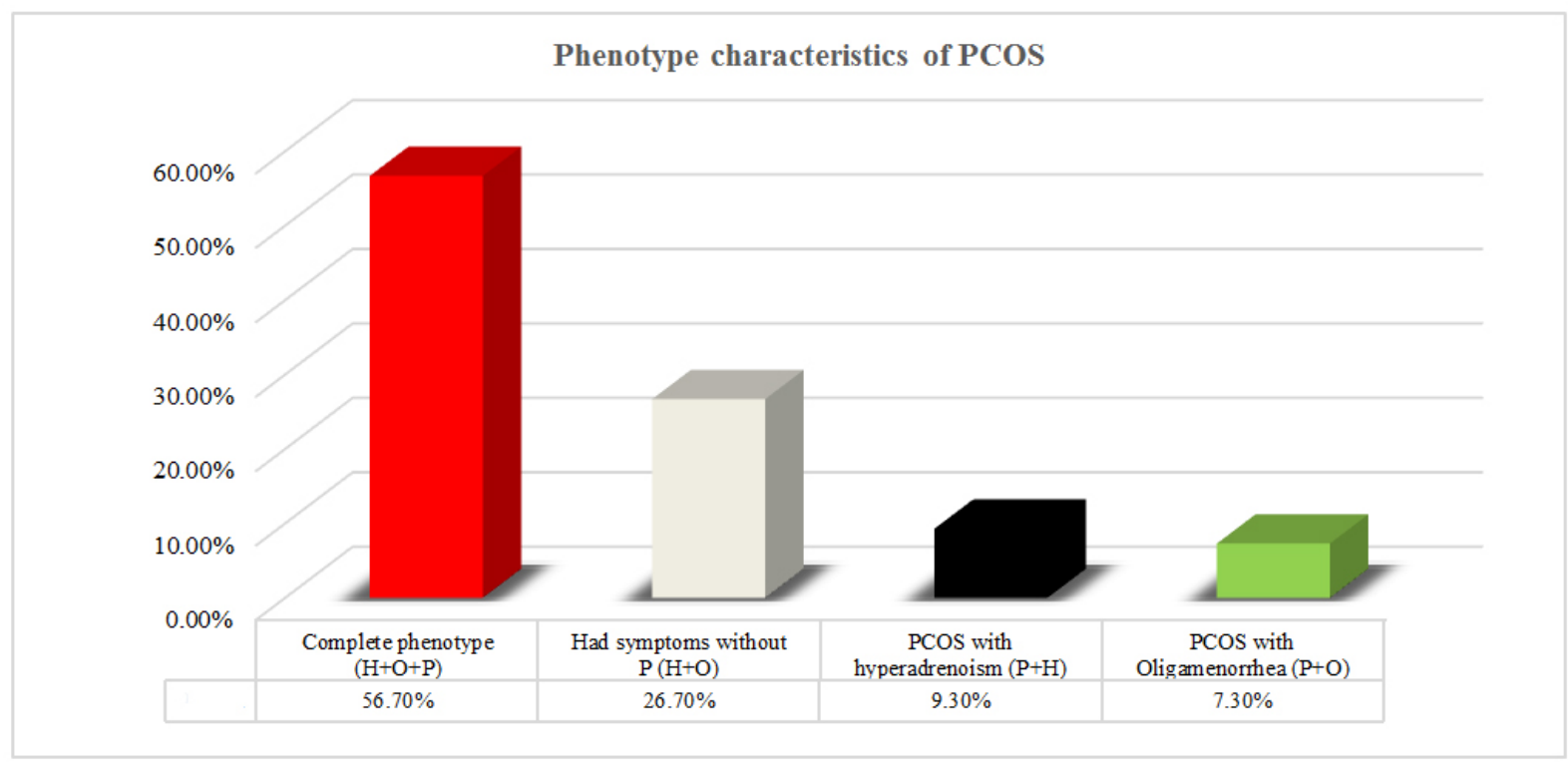

Figure 3. Phenotype characteristics of PCOS among the studied women $(n=300)$

As therefore set out to contrast women with PCOS into 4 subgroups: complete $\mathrm{PCOS}(\mathrm{O}+\mathrm{H}+\mathrm{P}), \mathrm{H}+\mathrm{P}$ with regular menses, $\mathrm{O}+\mathrm{H}$ with normal ovarian morphology, and $\mathrm{O}+\mathrm{P}$ in the absence of hyperandrogenism. Figure 3 shows that the most $(170 ; 56.7 \%)$ of women with PCOS had a complete phenotype $(\mathrm{H}+\mathrm{O}+\mathrm{P})$, and more than one quarter $(80 ; 26.7 \%)$ of them had symptoms without $\mathrm{P}(\mathrm{H}+\mathrm{O})$. On the other hand, a small proportion of women were suffered from PCOS with hyperadrenalism $(\mathrm{P}+\mathrm{H})$ and $\mathrm{PCOS}$ with oligomenorrhea $(\mathrm{P}+\mathrm{O}) ;(28 ; 9.3 \% \& 22 ; 7.3 \%)$, respectively.
Figure 4 Revealed that the majority $(240 ; 80.0 \%)$ of women had a positive ultrasound (cysts) and only $60 ; 20.0 \%$ had no cysts in the ovary.

Table 6 shows that the mean age in women with group 3 was lower than the other groups $(20.7 \pm 5.4)$. Moreover, women in the same group have a higher mean BMI and FerrimanGallwey Scores than the other three groups $(29.7 \pm 4.2 \&$ $15.9 \pm 2.8$, respectively).

While women with complete PCOS (group 1) have the high- 
est score $(94.5 \pm 5.6)$ of the average cycle length. It is tween the general assessment of women and characteristic evident that there are statistically significant differences be- of PCOS $(p \leq .05)$.

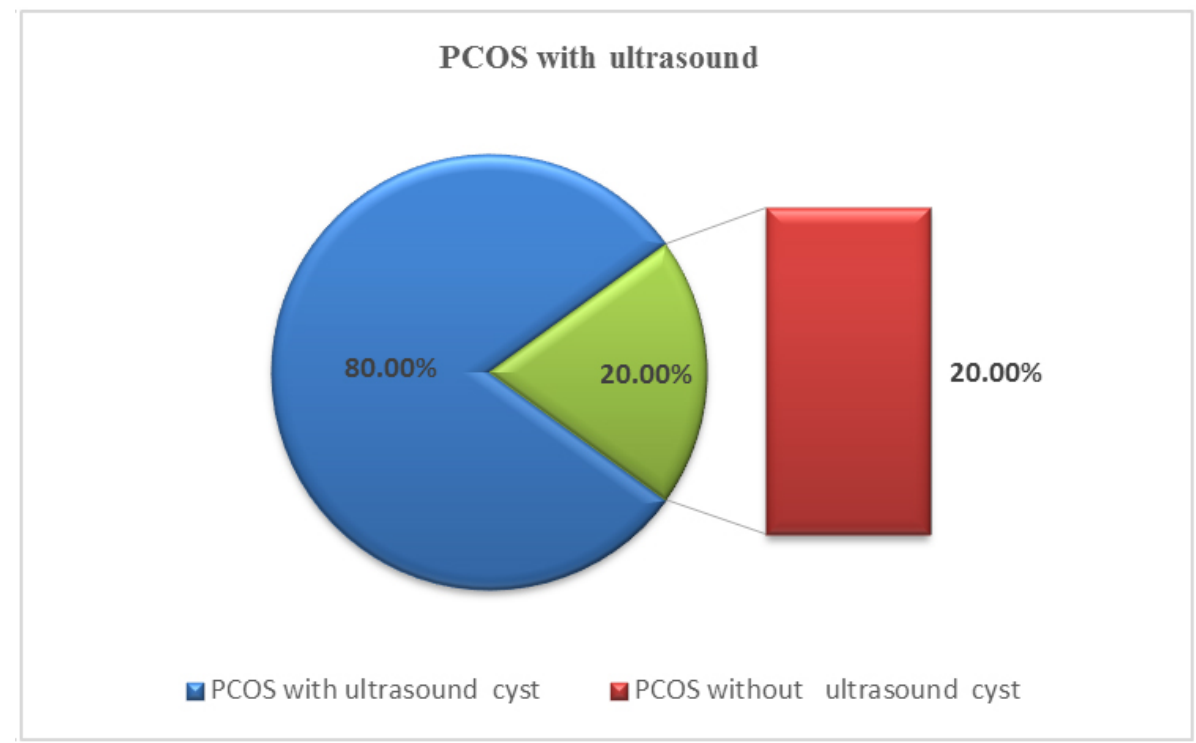

Figure 4. Positive cases of PCOS using ultrasound among the studied women $(n=300)$

Table 6. Relationship between the general assessment and phenotype characteristic of PCOS of the studied women $(\mathrm{n}=$ 300)

\begin{tabular}{|c|c|c|c|c|c|}
\hline Item & $\begin{array}{l}\text { Group (1) } \\
\mathrm{P}+\mathrm{H}+\mathrm{O}\end{array}$ & $\begin{array}{l}\text { Group (2) } \\
\mathrm{H}+\mathrm{O}\end{array}$ & $\begin{array}{l}\text { Group (3) } \\
\text { P+H }\end{array}$ & $\begin{array}{l}\text { Group (4) } \\
\mathrm{P}+\mathrm{O}\end{array}$ & $p$ \\
\hline Age & $24.9 \pm 5.8$ & $25.9 \pm 5.5$ & $20.7 \pm 5.4$ & $28.5 \pm 5.9$ & $<.05^{*}$ \\
\hline BMI & $27.9 \pm 4.5$ & $22.5 \pm 4.1$ & $29.7 \pm 4.2$ & $28.6 \pm 4.2$ & $<.05^{*}$ \\
\hline Ferriman-Gallwey Scores & $13.6 \pm 2.2$ & $5.8 \pm 1.9$ & $15.9 \pm 2.8$ & $5.8 \pm 1.9$ & $<.05^{*}$ \\
\hline Average cycle length (days) & $94.5 \pm 5.6$ & $34 \pm 7.1$ & $31.8 \pm 2.0$ & $39.5 \pm 0.6$ & $<.05^{*}$ \\
\hline
\end{tabular}

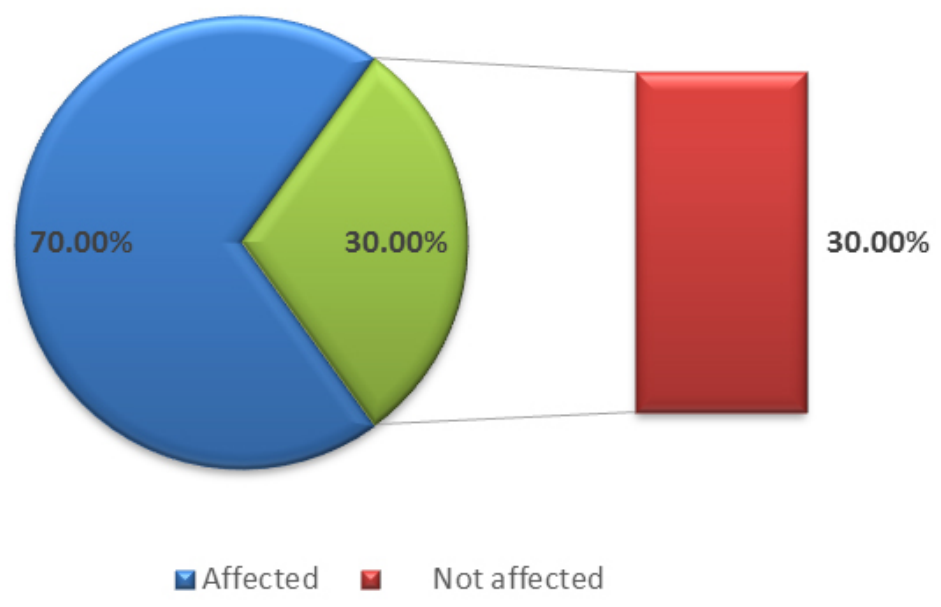

Figure 5. Level of QOL by SL-36 in the studied women 
Figure 5 displays the impact of the total QOL scale on women with PCO syndrome. It is obvious that nearly three-quarters $(210 ; 70.0 \%)$ of women their QOL had affected by PCO syndrome. Only $90(30.0 \%)$ of the women not affected.

Table 7 shows a summary of the total percentage scores of the six subscales of SF-36 in order of impact. Differences observed are statistically significant $(p<.05)$. It is evident that the poorest functioning was bodily pain $(80.0 \%)$ followed by women general health, energy and vitality, and physical functions $(63.4 \%, 60.0 \%, 57.4 \%)$, respectively.

Table 7. Distribution of the studied women according to their disturbance in physical-domain of QOL $(n=300)$

\begin{tabular}{|c|c|c|c|c|c|}
\hline \multirow{3}{*}{ Item } & \multicolumn{4}{|c|}{ Total impact of SL-36 } & \multirow{3}{*}{$p$} \\
\hline & \multicolumn{2}{|c|}{ Good } & \multicolumn{2}{|c|}{ Poor } & \\
\hline & No & $\%$ & No & $\%$ & \\
\hline Physical function & 128 & 42.6 & 172 & 57.4 & $<.05^{*}$ \\
\hline Energy and vitality & 120 & 40.0 & 180 & 60.0 & $<.05^{*}$ \\
\hline General health perception & 110 & 36.7 & 190 & 63.4 & $<.05^{*}$ \\
\hline Bodily pain & 60 & 20.0 & 240 & 80.0 & $<.001^{* * *}$ \\
\hline Role limit related to physical problems & 170 & 56.7 & 130 & 43.4 & NS \\
\hline
\end{tabular}

Note. Statistically significant at $p<.05 ;$ High statistically significant at $p<.001$

Table 8 shows that differences observed are highly significant ( $p \leq .001)$. Almost two-thirds of women with PCOS had a poor impact (negative) on the change in health $(67.0 \%)$ and social function (63.4\%) compared to only around one-third who had a good (positive) impact on the change in health $(33.0 \%)$ and social function $(36.6 \%)$.

Statistically, a significant difference was observed between PCOS and all items of SF-36 domain of women's QOL.

Table 8. Distribution of the studied women according to their disturbance in their psychological and social domain of QOL $(\mathrm{n}=300)$

\begin{tabular}{|c|c|c|c|c|c|}
\hline \multirow{3}{*}{ Item } & \multicolumn{4}{|c|}{ Total impact of SL-36 } & \multirow{3}{*}{$p$} \\
\hline & \multicolumn{2}{|c|}{ Good } & \multicolumn{2}{|c|}{ Poor } & \\
\hline & No & $\%$ & No & $\%$ & \\
\hline Mental health & 112 & 37.4 & 188 & 62.6 & $<.05^{*}$ \\
\hline Role limit related to emotional problems & 133 & 44.4 & 167 & 55.6 & $<.05^{*}$ \\
\hline Change in health & 99 & 33.0 & 201 & 67.0 & $<.001^{*}$ \\
\hline Social function & 110 & 36.6 & 190 & 63.4 & $<.001^{*}$ \\
\hline
\end{tabular}

Note. Statistically significant at $p<.05$

Table 9. Distribution of studied women according to knowledge before and after nursing guidelines about PCOS $(\mathrm{n}=300)$

\begin{tabular}{|c|c|c|c|c|}
\hline \multirow{3}{*}{ Knowledge areas } & \multicolumn{2}{|c|}{ Percent knowledge score $(M e a n \pm S D)$} & \multirow{3}{*}{$\begin{array}{c}\begin{array}{c}\text { Paired } \\
t \text {-test }\end{array} \\
\text { No }\end{array}$} & \multirow{3}{*}{$p$} \\
\hline & Pre $(n=300)$ & Post $(n=300)$ & & \\
\hline & No & $\%$ & & \\
\hline Definition \& Prevalence of PCOS & $2.25 \pm 1.53$ & $9.01 \pm 1.50$ & 59.72 & $<.001^{*}$ \\
\hline Etiology \& risk factors of PCOS & $2.25 \pm 1.53$ & $9.01 \pm 1.50$ & 40.54 & $<.001^{*}$ \\
\hline Diagnosis \& clinical features of PCOS & $1.13 \pm 1.17$ & $5.92 \pm 1.18$ & 40.13 & $<.001^{*}$ \\
\hline Complications \& risks of PCOS & $1.39 \pm 1.15$ & $5.80 \pm 1.10$ & 46.46 & $<.001^{*}$ \\
\hline laboratory investigation \& Management for of PCOS & $0.78 \pm 0.92$ & $5.63 \pm 1.17$ & 58.73 & $<.001^{*}$ \\
\hline Instructions \& recommendations for balanced \& healthy food & $2.11 \pm 1.12$ & $5.15 \pm 0.91$ & 39.24 & $<.001^{*}$ \\
\hline Total Mean score $($ Mean $\pm S D)$ & $9.01 \pm 4.69$ & $36.31 \pm 3.89$ & 73.12 & $<.001^{*}$ \\
\hline
\end{tabular}


Table 9 points to a highly statistically significant and a general improvement in all items of knowledge about PCOS at the post-test, $p<.001$ as compared to before program. On the other hand, the same table demonstrates a statistically significant improvement in women's total score of knowledge about PCOS at the post-test, $p<.001$.

\section{Discussion}

PCOS is a heterogeneous endocrinal-disorder of uncertain etiology. It is complex and a diverse female endocrine and metabolic disorder that affect women throughout their lifetime, leading to several health complications including menstrual irregularity/disorder, infertility, hirsutism, acne, obesity, and metabolic syndrome. ${ }^{[33]}$ The adverse impact of this heterogeneous condition on psychological features (worsen QOL, depression, and anxiety) has become an important indicator of research in the recent last decade. ${ }^{[34]}$ However, data on women's experience of common PCOS problems and their impact on QOL in Beni-Suef is scanty, therefore, the aim of the study was to determine the impact of PCOS on QOL among the studied women.

According to Fauser et al., PCOS affects $7.0 \%$ of reproductive-aged women (newer criteria have it at $10.0 \%$ ), ${ }^{[6]}$ while March et al. mentioned that it occurs in $12.0 \%$ to $21.0 \%$ of reproductive-age women, among those who are obese/overweight. ${ }^{[2]}$ In Australia, Azziz et al. found that the prevalence was $11.0 \%$ of Australian women and $21.0 \%$ of Australian indigenous women. ${ }^{[35]}$ In European studies, it reported by Farquhar et al. that the prevalence of PCOS was $6.5 \%$ to $8.0 \% .{ }^{[36]}$ On the other hand, Carmina et al. in USA found that the prevalence was $6.0 \%$ to $8.0 \%$ of women. Although the prevalence may be as high as $30.0 \%$ in women with secondary amenorrhea, $75.0 \%$ in women with oligomenorrhea, and $90.0 \%$ in women with hirsutism. ${ }^{[37]}$

The current study revealed that the mean age of women with PCOS was 25.0 years old. This is matching with Wijeyaratne et al., who found that the average age of women with PCOS ranges between 25 and 26 years. ${ }^{[38]}$ On the hand, Bazarganipour et al. from Iran found that the average age of women with PCOS was 28.2 years. ${ }^{[39]}$ The present study revealed that a considerable percent of the studied women was illiterate, housewives and married $(43.0 \%, 61.0 \%, 63.4 \%)$, respectively. This finding is coinciding with Bazarganipour et al., who found that the majority of their studied subjects had been housewives and married. ${ }^{[39]}$ On the contrary, the study of Elsenbruch et al. in German revealed that the majority of the studied patients had a college-degree and were working. ${ }^{40]}$ The contradiction among the various studies addressing the above-mentioned socio-economic factors and the present one has been attributed to inclusion criteria and the cultural background of the studied subjects.

The phenotype characteristics of PCOS based on the history and the clinical examination of women in the study sample, as noted in the current study, in which the most common phenotype was complete phenotype $(56.7 \%)$ and the less group is $\mathrm{P}+\mathrm{O}(7.3 \%)$. This result was supported by Garad et al., who found the most common phenotype was complete phenotype and the less group $(5.4 \%)$ is $(\mathrm{O}+\mathrm{P}) .{ }^{[41]}$ Age of the women is impotent factors that may be associated with the phenotype of PCOS. In the current study, women who had a phenotype $(\mathrm{P}+\mathrm{H})$ were significantly more likely to be lower than 22 years compared with phenotype $(\mathrm{P}+\mathrm{O})$. This result was in line with Shroff et al. who reported that significant association between the phenotype of PCOS and the advanced women age, but wasn't in harmony with the same researcher who reported in his study that the average age of women with $\mathrm{O}+\mathrm{P}$ was 28.2 years. ${ }^{[42]}$ Additionally, Zhang et al.in China stated that no significant association was found between the phenotype of PCOS and the advanced women age. $^{[43]}$

The present study findings revealed that women with higher BMI, overweight and obese $(48.1 \%)$ were more likely to have PCOS. This has a significant effect on the phenotype characteristic of PCOS as well as the quality of women's life and leads to poor QOL. Our results were in the same vein with Bazarganipour et al. in USA, and Louwers et al. who mentioned that a significant association with weight and QOL. ${ }^{[39,40]}$

Many factors are mentioned to be associated with PCOS as; hirsutism, acne, alopecia, insulin resistance. Our study findings declare that PCOS is the common risk factor for the previously mentioned features. Mustache hair (44.9\%) and facial hair $(28.6 \%)$ ratio were the most important predictors of PCOS in women with hirsutism. Furthermore, around two-thirds of women $(65.0 \%)$ had suffered from alopecia problem. Our findings revealed that $9.3 \%$ of the studied women suffered from acne. This corresponds well with the finding of Trent et al., who reported a significant relationship between acne and PCOS. ${ }^{[45]}$ On the other hand, Zandi et al. mentioned that the polycystic ovarian syndrome is a common disorder in the Iranian women with acne and not necessarily associated with clinical signs and symptoms such as hirsutism or obesity. ${ }^{[46]}$

In the current study, many factors to be associated with the phenotype of PCOS as: BMI, hirsutism and average cycles length, women who had $\mathrm{H}+\mathrm{O}$ were significantly more likely to have the lowest BMI $(22.5 \pm 4.1, p<.05)$, and Ferriman-Gallwey scores $(5.8 \pm 1.9, p<.05)$. This finding is in accordance with Zhang et al. and Moran et al., 
who mentioned a significant association between the PCOS phenotypes and the BMI \& Ferriman-Gallwey Scores. ${ }^{[44,47]}$ Furthermore, patients with complete PCOS have statistically the highest score $(94.5 \pm 5.6)$ of the average cycle length. A similar finding was reported by Moran et al., they have mentioned that significant association was evident between the phenotype of PCOS and menstrual irregularity. ${ }^{[47]}$

When the menstrual history, of the participant women, was studied, the results declared that three-quarters $(75.0 \%)$ of the studied sample were had early menarche with the mean age $13.3 \pm 1.2$. This is in line with VAN Hooff et al. from Amsterdam who found that the mean age of menarche is 13.3 years. ${ }^{[48]}$ On the contrary, late menarche was noticed by Trent et al. in Boston, and Zandi et al. in Iran study (15 years). ${ }^{[45,46]}$ In this respect, Nazeema et al. mentioned that the mean age at menarche varies from population to population and is known to be a sensitive indicator of various characteristics including geographical location, environmental conditions, nutritional status in society. ${ }^{[49]}$

The present study has also revealed that more than half $(58.7 \%)$ of the studied women had irregular menstruation and $78.0 \%$ of them suffered from oligomenorrhea. This corresponds well with Zandi et al., who reported that 59.4\% and $61.3 \%$ of their studied subjects had irregular menstruation and oligomenorrhea. ${ }^{[46]}$ In contrast, Wild et al. in Colombo stressed that the vast majority of his study subjects complained of irregular menstruation and $49.5 \%$ had oligomenorrhea. ${ }^{[50]}$ As regards menstrual pain $63.3 \%$ of studied subjects reported severe menstrual pain in all PCOS phenotypes. This result corresponds well with Pinto et al., who found that there is a strong association between endometriosis "which is common in PCOS women" and pelvic pain. ${ }^{[51]}$ The difference between the present study and the previous studies might be related to the difference in the sample size and failure to adjust for confounding factors in assessing the effect of PCOS on menstruation.

Moreover, bodily pain domain was shown as the highest negative effect $(80.0 \%)$ on QOL followed by women's general health $(63.4 \%)$, energy and vitality $(60.0 \%)$, and physical functions $(57.4 \%)$. Statistically, a significant relationship was found between all domains of women's physical health and the total impact of SL-36. These results are in agreement with Dilbaz, who mentioned that, by using the SL-36; the lowest mean total score and worst area of HRQOL for the South-Asian group was observed for general health. ${ }^{[52]} \mathrm{On}$ the contrary, Ching et al. reported that women with PCOS had significantly decreased scores, indicating lower QOL, on the SL-36 scales; physical function, physical role function, bodily pain and vitality. ${ }^{[33]}$
The prevalence of nulliparity among women with PCOS in the current study was $53.7 \%$. These findings in partial supported with Pembe \& Abeid in Tanzania, who found that the frequency of nulliparous women with PCOS was $62.5 \% .^{[54]}$ Also, the present study revealed that $36.0 \%$ of women with PCOS had of previous abortion. This is matching with Norman et al., the study in Australia who noted the high-risk of spontaneous-abortion in women with PCOS, and they related this to the high prevalence of obesity and the treatment type they received. ${ }^{[55]}$

The findings of current study revealed that $11.3 \%$ of the studied women had a history of complication during pregnancy which in form of gestational diabetes mellitus (GDM; $64.7 \%$ ) and pregnancy-induced-hypertension (PIH; 35.3\%). This may be attributed to unhealthy dietary habit associated with PCOS and the lack of exercise. Similar results were also reported by Vollenhoven et al., who found an increased incidence of GDM among PCOS patients. ${ }^{[56]}$ Meanwhile, Chen et al. confirmed the relationship between the higher androgens level and blood pressure in women with PCOS who aren't obese. ${ }^{[57]}$

As shown in the present study, almost half $(48.0 \%)$ of the studied women suffered from infertility problem and $62.7 \%$ used ovarian stimulation. Infertility treatment covers a variety of treatment modalities for patients with different etiology and involves different types and doses of drugs for ovarian stimulation. This corresponds well with Atay et al., who mentioned that the use of ovarian stimulation was present in $63.6 \%$ of women with PCOS. ${ }^{[58]}$ In the contract, Pembe et al. in Tanzania reported a higher rate of infertility $(53.1 \%)$ among the studied women with PCOS. ${ }^{[54]}$

Familial clustering of PCOS has been consistently reported suggesting that genetic factors play a role in the development of this syndrome. ${ }^{[59]}$ In the current study, more than one-half of women $(62.0 \%)$ had a positive family history of PCO syndrome. Of those, the mother constituted the highest percentage $(40.9 \%)$ followed by the sister $(27.9 \%)$, mother's sister $(20.5 \%)$, and father's sister $(10.7 \%)$. This finding is consistent with Diamanti-Kandarakis et al., who studied Birmingham, Alabama 218 PCOS patients using the current ESHRE/ASRM criteria for PCOS. They noticed that $77.0 \%$ possessed female relative with PCOS, half of the mothers and fourth of the sisters. This was matching with an autosomal dominant with variable phenotype inheritance. ${ }^{[60]}$

The current stud revealed that more than three-quarters $(80.0 \%)$ of women had evidence of cysts by ultrasonographic examination. Similarly, Dewailly et al. found that more than three-quarters of Asian women had evidence of cysts by ultrasound, these results indicating a diminished QOL. ${ }^{[61]}$ 
This explained the fact that QOL had affected by PCO syndrome. Similarly finding by Jones et al. was reported that common benign gynecological condition including PCOS were major sources of physical and psychological morbidity and typically lead to overall diminished QOL. ${ }^{[18]}$

The results of the study have also declared that almost twothirds (67.0\% \& 63.4\%, respectively) of women with PCOS had poor (negative) impact on the change in health and social function, compared to only one-third $(33.0 \%$ \& $36.6 \%)$ who had good (positive) impact on the same variables. Moreover, $62.6 \%$ \& $55.6 \%$ had poor impact on mental health and role limitation, compared to $37.4 \%$ \& $44.4 \%$ who had good ones. This finding conformity with Hahn et al., who mentioned that the women with PCOS had a negative impact on social function than mental health. ${ }^{[62]}$ Moreover, these results aren't in harmony with Elsenbruch et al., who stated that women with PCOS had a negative impact on role limitation/emotion and change in health. ${ }^{[63]}$

A woman's QOL, which negatively affect a woman's social functioning and relationships with her partner/family, might be adversely affected by PCOS. Health-care providers should address the severity of women's symptoms in relation to their QOL and social situation. ${ }^{[64]}$ In women with PCOS, an input may be required from other professionals, such as gynecologist, nurse, dietician/nutritionist. Nurses are the base-stone of the health-care system and comprising the greatest portion of this existence. They are responsible for women's lifespan quality-of-care. As the researchers affiliated to maternity nursing branch, therefore, they played a crucial role in gynecologic clinics in providing women with a clear and accurate information regarding PCOS. They encourage them to ask their questions to get their need information to enhance their QOL. Educating the clients is a role for nurses in all health care settings; the nurse is often the main source of information about health promotion that is why they have a very important role in the current educational guidelines. ${ }^{[65-68]}$ Therefore, this guideline aimed to increase women's awareness regarding PCOS and its appropriate management.

Regarding the effect of nursing guidelines about PCOS, the results of the present study clarify an improvement of women's knowledge in allover items (definition, prevalence, etiology, risk factors, diagnosis \& clinical features, complications, laboratory investigation, management, instructions $\&$ recommendations for balanced and healthy food) with a highly significant relation $(p<.001)$. Moreover, the total mean score (Mean $\pm S D$ ) of women's knowledge was improved from $9.01 \pm 4.69$ to $36.31 \pm 3.89$, a high statistical difference was observed $(p<.001)$. This improvement reflects the effect of the implementation of nursing guidelines. The progress of knowledge's score may be attributed to wide varieties of educational methods used by the researcher as audiovisual materials, pamphlets, lectures, videos, and discussion as well as Arabic booklet. ${ }^{[69]}$ This is in accordance with Edgar Dale's or the NTL's Pyramid of Learning as cited by many authors as the pyramid illustrated that individuals can retain $50 \%$ of what he discussed, $20 \%$ of what he sees/hear, and $10 \%$ of what he read. ${ }^{[70-72]}$

\section{Conclusions}

Polycystic ovarian syndrome is a common risk factor for acne, alopecia, insulin resistance hirsutism. Mustache hair and facial hair ratio were the most important predictors of PCOS in women with hirsutism. Many factors to be associated with the phenotype of PCOS as; BMI, hirsutism and average cycles length. Over-weight/obesity (BMI) was the most risk factor for PCOS. PCOS has a negative impact on phenotype characteristic, psychological and social domain of QOL, and the total QOL scale leading to poor women's QOL. The implemented nursing guideline had a crucial role in the improvement of women's knowledge in allover items and total mean score (mean $\pm S D$ ) of women's knowledge, a high statistical difference was observed.

\section{Recommendations}

Based on the foregoing study results, the following recommendations are suggested:

1. Upgrading women's knowledge concerning PCOS with a periodic screening of women for early detection and management of PCOS.

2. Nurses in gynecologic and obstetrics clinics should organize educational sessions for adolescents regarding PCOS concerning the causes, symptoms and signs and the management, with the development of teaching materials in the form of posters and booklets.

3. Health promotion programs through different media to improve QOL for women with PCOS.

\section{CONFlicts OF InTEREST Disclosure}

The authors declare they have no conflicts of interest. 


\section{REFERENCES}

[1] Leonhardt H. Polycystic ovary syndrome: a complex condition with psychological, reproductive and metabolic manifestations that impact on health across the lifespan. BMC Medicine. 2014; 8: 41.

[2] March W, Moore V, Willson K, et al. The prevalence of polycystic ovary syndrome in a community sample assessed under contrasting diagnostic criteria. Hum. Reprod. 2010; 25: 544-5. PMid: 19910321. https ://doi.org/10.1093/humrep/dep399

[3] Teede H, Misso M, Deeks A, et al. Assessment and management of polycystic ovary syndrome: summary of an evidence-based guideline. Med. J. 2011; 195: S65-112. https ://doi .org/10.5694/mja11. 10915

[4] Shannon M, Wang Y. Polycystic ovary syndrome: a common but often unrecognized condition. J. Midwifery Women's Health. 2012; 57(3): 221-30. PMid: 22594862. https ://doi.org/10.1111/j. 1542-2011.2012.00161.x

[5] Goodarzi M, Dumesic D, Chazenbalk G, et al. Polycystic ovary syndrome: Etiology, pathogenesis and diagnosis. Nature Reviews Endocrinology. 2011; 7: 219-231. PMid: 21263450. https://doi. org/10.1038/nrendo.2010.217

[6] Fauser B, Tarlatzis B, Rebar R, et al. Definitions, prevalence and symptoms of polycystic ovaries and the polycystic ovary syndrome. Kent, UK: Anshan, Ltd. 2012; 18-28.

[7] American College of Obstetricians and Gynecologists (ACOG). Polycystic ovary syndrome. 2012(2): 670-689.

[8] Jedel E, Waern M, Gustafson D, et al. Anxiety and depression symptoms in women with polycystic ovary syndrome compared with controls matched for body mass index. Hum. Reprod. 2010; 25(2): 450-456. PMid: 19933236. https://doi.org/10.1093/humrep /dep384

[9] Deeks A, Gibson-Helm M, Teede H. Anxiety and depression in polycystic ovary syndrome: A comprehensive investigation. Fertil. Steril. 2010; 93(7): 2421-2423. PMid: 20117778. https: //doi.org/10.1016/j.fertnstert.2009.09.018

[10] Emem E, Hassan H. Correlation between Quality of Life and Dysmenorrhea among Nursing Schools Students. International Journal of Nursing Science. 2017; 7(6): 123-132.

[11] Mohammed F, Shahin M, Youness E, et al. Survivorship in Women Undergoing Gynecological and Breast Cancer Treatment in Upper Egypt: The Impact of Quality of Life Improvement Educational Program. American Research Journal of Gynecology. 2018; 2(1): $1-28$.

[12] Mostafa H, Yousef F, Hassan H. Health Related Quality of Life Educational Interventions: Effect on Chronic Hepatitis C Patients. Saudi Journal of Nursing and Health Care. 2018; 1(2): 56-67.

[13] Nady F, Said M, Youness E, et al. Impact of Tailored Educational Program of Quality of Life Improvement on Women Undergoing Breast Cancer Treatment at El-Minia Region, Egypt. American Research Journal of Gynaecology. 2017; 1(1): 1-17.

[14] Nady F, El-Sherbiny M, Youness E, et al. Effectiveness of Quality of Life Planned Teaching Program on Women Undergoing Gynecologic Cancer Treatment. American Research Journal of Oncology. 2018; 1(1): 1-17.

[15] The WHOQOL Group. The World Health Organization Quality of Life assessment (WHOQOL): position paper from the World Health Organization. Soc. Sci. Med. 2005; 52: 1406.

[16] Weaver K, Forsythe L, Reeve B. Mental and physical health-related quality of life among U.S. cancer survivors: population estimates Cancer Epidemiol Bio-markers Prev. 2012; 21: 2108-2117. PMid: 23112268. https ://doi.org/10.1158/1055-9965.EPI-12-0 740

Published by Sciedu Press
[17] Yarbro C, Frogge M. Cancer Nursing Principle: in "Breast Cancer", 6th ed. Bartleelt: Bosten; 2006. 190 p.

[18] Jones G, Kennedy S, Jenkinson C. Health-related quality of life measurement in women with common benign gynecologic conditions: A systemic review. American Journal of Obstetrics and Gynecology. 2002; 187(2): 501-511. PMid: 12193950. https : //doi.org/10.1067/mob.2002.124940

[19] Kobau R, Sniezek J, Zack M, et al. Well-being assessment: an evaluation of well-being scales for public health and population estimates of well-being among US adults. Health and Well-Being. 2010 https://doi.org/10.1111/j.1758-0854.2010.01035.x

[20] Badawy A, Elnashar A. Treatment options for polycystic ovary syndrome. Int J Womens Health. 2011; 3: 25-35. PMid: 21339935. https://doi.org/10.2147/IJWH.S11304

[21] Tang T, Lord J, Norman R, et al. Insulin-sensitising drugs (metformin, rosiglitazone, pioglitazone, d-chiro-inositol) for women with polycystic ovary syndrome, oligoamenorrhoea, and subfertility. Cochrane Database Syst. Rev. 2012; 5: CD003053. https: //doi.org/10.1002/14651858.CD003053.pub5

[22] Sheha E, Hassan H, Gamel W. Association between pre-pregnant overweight and obesity and periodontal disease during pregnancy: a cross sectional study. International Journal of Studies in Nursing 2018; 3(1): 1-21. https ://doi.org/10.20849/ijsn.v3i1. 207

[23] Said S, Hassan H, Sarhan A. Effect of an Educational Intervention on Women's Knowledge and Attitude Regarding Cervical Cancer. American Journal of Nursing Research. 2018; 6(2): 59-66.

[24] Eid S, Hassan H, Fathy W, et al. Study Women Verbal and Nonverbal Response, During Their First Gynecological Examination. American Journal of Nursing Research. 2019; 7(1): 1-7.

[25] Hassan H, Saber N, Sheha E. Comprehension of Dyspareunia and Related Anxiety among Northern Upper Egyptian women: Impact of Nursing Consultation Context Using PLISSIT Model. Nursing \& Care Open Access Journal. 2019; 6(1): 1-19.

[26] Karen T, Lesley B, Hallam F, et al. QOL in women with PCOS Human Psychopharmacology: Clinical and Experimental. 2010; 25(2): 192. https://doi.org/10.1002/hup.1107

[27] Atwa A, Hassan H, Ahmed S. The impact of a hospital-based awareness program on the knowledge of patients about breast cancer and cancer cervix. International Journal of Studies in Nursing. 2019; 4(1): 20-29. https://doi .org/10.20849/ijsn.v4i1.537

[28] Mohamed A, Hassan H, Gamel W, et al. Awareness about breast and cervical cancers among nursing students in Beni-Suef University. Journal of Nursing Education and Practice. 2019; 9(5): 44-51. https://doi.org/10.5430/jnep.v9n5p44

[29] Campbell J. Pain: the fifth vital sign, 1995 [presidential address]. American Pain Society. Available from: http://www.ampainsoc. org

[30] Ferriman D, Gallwey J. Clinical assessment of body hair growth in women. J. Clin. Endocrinol. 1961; 21: 1440-1447. PMid: 13892577. https ://doi.org/10.1210/jcem-21-11-1440

[31] Colwell H, Mathias S, Pasta D, et al. A health related quality of life instrument for symptomatic patients with endometriosis: a validation study. Am. J. Obstet. Gynecol. 1998; 179: 47-55. https : //doi.org/10.1016/S0002-9378(98)70250-9

[32] Montazeri A, Goshtasebi A, Vahdaninia M, et al. The Short Form Health Survey (SF-36) translation and validation study of the Iranian version. Qual. Life Res. 2005; 14: 875-882. PMid: 16022079. https://doi .org/10.1007/s11136-004-1014-5

[33] Zhao H, Lv Y, Li L, et al. Genetic Studies on Polycystic Ovary Syndrome. Best Practice \& Research Clinical Obstetrics \& Gynaecology. 2016; 37: 56-65. PMid: 27264388. https://doi.org/10.1016/ j.bpobgyn . 2016.04.002 
[34] Livadas S, Diamanti-Kandarakis E. Polycystic ovary syndrome: definitions, phenotypes and diagnostic approach. Front Horm Res. 2013; 40: 1-21. PMid: 24002401. https://doi.org/10.1159/000341 673

[35] Azziz R, Carmina E, Dewailly D, et al. The androgen excess and PCOS society criteria for the polycystic ovary syndrome: The complete task force report. Fertil. Steril. 2009; 91: 456-488. PMid: 18950759. https://doi.org/10.1016/j.fertnstert .2008 .06 .035

[36] Farquhar C, Birdsall M, Manning P, et al. The prevalence of polycystic ovaries on ultrasound scanning in a population of randomly selected women. J. Obstet. Gynaecol. 2007; 34: 67-72. PMid: 8053879. https://doi.org/10.1111/j.1479-828X.1994.tb01041.x

[37] Carmina E, Napoli N, Longo R, et al. Metabolic syndrome in polycystic ovary syndrome (PCOS) lower prevalence in southern Italy than in the USA and the influence of criteria for the diagnosis of PCOS. Eur. J. Endocrinol. 2006; 154: 141-145. PMid: 16382003. https://doi.org/10.1530/eje.1.02058

[38] Wijeyaratne CN, Seneviratne RDA, Dahanayake S, et al. Phenotype and metabolic profile of South Asian women with polycystic ovary syndrome (PCOS): results of a large database from a specialist Endocrine Clinic. Human Reproduction. 2011; 26(1): 202-213. PMid: 21098627. https ://doi.org/10.1093/humrep/deq310

[39] Bazarganipour F, Ziaei S, Montazeri A, et al. Psychometric properties of the Iranian version of modified polycystic ovary syndrome health-related quality-of-life questionnaire Human Reproduction. 2012; 27(9): 1-8. PMid: 22740491. https://doi.org/10.109 3/humrep/des 199

[40] Elsenbruch S, Hahn S, Kowalsky D, et al. Quality of Life, Psychosocial Well-Being, and Sexual Satisfaction in Women with Polycystic Ovary Syndrome. Journal of Clinical Endocrinology \& Metabolism. 2003; 88(12): 5801-5807. PMid: 14671172. https: //doi.org/10.1210/jc.2003-030562

[41] Garad R, Teede J, Helena J, et al. An evidence-based guideline for polycystic ovary syndrome. Australian Nursing Journal: A.N.J. 2011; 19(4): 30-33

[42] Shroff R, Syrop C, Davis W, et al. Risk of metabolic complications in the new PCOS phenotypes based on the Rotterdam criteria. Fertility and Sterility. 2007; 88(5): 534-540. PMid: 17462641 https://doi.org/10.1016/j.fertnstert.2007.01.032

[43] Zhang H, Zhu F, Xiong J, et al. Characteristics of different phenotypes of polycystic ovary syndrome based on the Rotterdam criteria in a large-scale Chinese population. An International Journal of Obstetrics and Gynaecology (BJOG). 2009; 116: 1633-1639. PMid: 19781047. https://doi.org/10.1111/j.1471-0528.2009.02347.x

[44] Louwers Y, Rayner N, Herrera B, et al. BMI-associated alleles do not constitute risk alleles for the Polycystic Ovary Syndrome independently of BMI: a case-control study. Plos One. 2014; 90: 384049. PMid: 24498077. https ://doi.org/10.1371/journal.po ne. 0087335

[45] Trent M, Rich M, Austin S, et al. Quality of life in adolescent girls with polycystic ovary syndrome. Arch Pediatr Adolesc Med. 2002; 156(6): 556-60. PMid: 12038887. https://doi.org/10.1001/ archpedi.156.6.556

[46] Zandi S, Farajzadeh S, Safari H. Hiurtism and acne in women with PCOS. Journal of Pakistan Association of Dermatologists. 2010; 20: 194-198.

[47] Moran C, Arriaga M, Rodriguez G, et al. Obesity Differentially Affects Phenotypes of Polycystic Ovary Syndrome. International Journal of Endocrinology. 2012; 1-7. PMid: 22829818. https: //doi.org/10.1155/2012/317241
[48] van Hooff D, Feja J, Voorhorst M, et al. Polycystic ovaries in adolescents and the relationship with menstrual cycle patterns, luteinizing hormone, androgens, and insulin. Fertility and Sterility. 2000; 74(1). https://doi .org/10.1016/S0015-0282(00)00584-7

[49] Nazeema P, Manju L, Anil S, et al. Menstrual problems among adolescent girls in Thiruvananthapuram district. Int J Community Med Public Health. 2017; 4(8): 2995-2998. https : //doi.org/10. 182 03/2394-6040.ijcmph20173360

[50] Wild R, Carmina E, Diamanti K, et al. Assessment of cardiovascular risk and prevention of cardiovascular disease in women with the polycystic ovary syndrome: a consensus statement by the Androgen Excess and Polycystic Ovary Syndrome (AE-PCOS). Society. J Clin Endocrinol Metab. 2010; 95: 2038-2049. PMid: 20375205. https://doi.org/10.1210/jc.2009-2724

[51] Pinto S, Garden A. Prepubertal menarche: a defined clinical entity. Am. J. Obstet Gynecol. 2006; 195: 327. PMid: 16813762. https://doi.org/10.1016/j.ajog.2005.09.005

[52] Dilbaz B, Çınar M, Özkaya E, et al. Health related quality of life among different PCOS phenotypes of infertile women. J. TurkishGerman Gynecol. 2012; 13: 247-52. PMid: 24592051. https: //doi.org/10.5152/jtgga.2012.39

[53] Ching H, Burke V, Stuckey B. Quality of life and psychological morbidity in women with polycystic ovary syndrome: body mass index, age and the provision of patient information are significant modifiers. Clin. Endocrinol (Oxf). 2007; 66: 373-379. PMid: 17302871. https://doi.org/10.1111/j.1365-2265.2007.02742.x

[54] Pembe A, Abeid M. Polycystic ovaries and associated clinical and biochemical features among women with infertility in a tertiary hospital in Tanzania. Tanzania Journal of Health Research. 2009; 11(4). https://doi.org/10.4314/thrb.v11i4.50172

[55] Norman R, Masters L, Milner C, et al. Relative risk of conversion from normoglycaemia to impaired glucose tolerance or non-insulin dependent diabetes mellitus in polycystic ovarian syndrome. Hum. Reprod. 2001; 16: 333-339. PMid: 11527911. https://doi.org/ 10.1093/humrep/16.9.1995

[56] Vollenhoven B, Clark S, Kovacs G, et al. Prevalence of gestational diabetes mellitus in polycystic ovarian syndrome (PCOS) patients pregnant after ovulation induction with gonadotrophins. Aust N. Z. J Obstet Gynaecol. 2008; 40(1): 54-8. PMid: 10870780. https://doi.org/10.1111/j.1479-828X.2000.tb03167.x

[57] Chen M, Yang W, Yang J, et al. Relationship between androgen levels and blood pressure in young women with polycystic ovary syndrome. Hypertension. 2007; 49: 1442-1447. PMid: 17389259. https://doi.org/10.1161/HYPERTENSIONAHA.106.083972

[58] Atay V, Cam C, Muhcu M, et al. Comparison of letrozole and clomiphene citrate in women with polycystic ovaries undergoing ovarian stimulation. J. Int. Med. Res. 2006; 34: 73-76. PMid: 16604826. https://doi .org/10.1177/147323000603400109

[59] Unluturk U, Harmanci A, Kocaefe C, et al. The The Genetic Basis of the Polycystic Ovary Syndrome: A Literature Review Including Discussion of PPAR-gamma. 2007; 49109. PMid: 17389770. https : //doi .org/10.1155/2007/49109

[60] Diamanti-Kandarakis E, Kandarakis H, Legro R. The role of genes and environment in the etiology of PCOS. Endocrine. 2006; 30(1): 19-26. https ://doi .org/10.1385/ENDO:30:1:19

[61] Dewailly D, Gronier H, Poncelet E, et al. Diagnosis of polycystic ovary syndrome (PCOS): revisiting the threshold values of follicle count on ultrasound and of the serum AMH level for the definition of polycystic ovaries. Hum. Reprod. 2011; 26(11): 3123-3129. PMid: 21926054. https : //doi.org/10.1093/humrep/der297

[62] Hahn S, Janssen O, Tan S, et al. Clinical and psychological correlates of quality-of-life in polycystic ovary syndrome. European 
Journal of Endocrinology. 2005; 153: 853-860. PMid: 16322391. https://doi.org/10.1530/eje.1.02024

[63] Elsenbruch S, Benson S, Hahn S, et al. Determinants of emotional distress in women with polycystic ovary syndrome. Hum. Reprod. 2006; 21: 1092-9. PMid: 16459352. https://doi .org/10.1093/ humrep/dei409

[64] Farg D, Hassan H. Risk Factors for Hyperemesis Graviderum Requiring Hospital Admission during Pregnancy and Nursing Implication. American Journal of Nursing Research. 2019; 7(3).

[65] Nasr E, Hassan H. Association between quality of family planning services and client's satisfaction level in maternal and child health centers in Port Said city. Journal of Nursing Education and Practice. 2016; 6(1): 85-99. https://doi.org/10.5430/jnep.v6n1p85

[66] Abd-Allah N, Nasr E, Hassan H. Impact of a Breast-Feeding Educational Program for Mothers Having Pre-Term Infants in General Hospitals in Port Said. International Journal of Novel Research in Healthcare and Nursing. 2017; 4(3): 215-225.

[67] Hassan H, Gamel W, El-Gawad A, et al. Menstrual disorders necessitating counseling among students in Beni-Suef University. Clinical Nursing Studies. 2019; 7(2): 29-36. https ://doi .org/10.5430/ cns. v7n2p29
[68] Farag D, Hassan H. Maternal Postpartum Sleep disturbance and Fatigue: Factors Influencing. ARC Journal of Nursing and Healthcare. 2019; 5(2): 27-40. http://doi.org/10.20431/2455-4324.05 02004

[69] Hassan H, Mohamady S, Abd El-Gawad N. Protocol for improving nursing performance towards placental examination at labor units. Clinical Nursing Studies. 2017; 5(2): 1-11. https://doi.org/10 $.5430 / \mathrm{cns} . \mathrm{v} 5 \mathrm{n} 2 \mathrm{p} 1$

[70] Hassan H. Effectiveness of a structured teaching program on anxiety and perception regarding toxoplasmosis among seropositive pregnant women in Northern Upper Egypt. Clinical Nursing Studies. 2018; 6(1): 1-19. https://doi.org/10.5430/cns.v6n1p1

[71] Hassanine S, Hassan H, Alkotb Z. Effect of Preventive Program on Progression of Osteoporosis among Female Patients over 40 years at El-Fayoum City. American Research Journal of Nursing. 2017; 3(1): $1-15$.

[72] Hassan H, Nasr E. Improving nurses' knowledge and skills regarding tocolytics for inhibiting preterm labor. Clinical Nursing Studies. 2017; 5(1): 1-12. https://doi.org/10.5430/cns.v5n1p1 